with rectal carcinoma of Dukes's stages B and C should receive adjuvant radiotherapy or radiotherapy and chemotherapy, convincing evidence from published randomised trials to support this view is lacking.

Western General Hospital, Edinburgh EH12 5BY

PETER BLISS

1 Begent RHJ. Colorectal cancer. BMf 1992;305:246-9. (25 July ) Gérard A, Buyse M, Norlinger B, Loygue J, Pene F, Kempf $P$, et al. Preoperative radiotherapy as adjuvant treatment in rectal cancer. Ann Surg 1988;208:606-14.

3 Stockholm Rectal Cancer Study Group. Pre-operative short term radiation therapy in operable rectal carcinoma. Cancer 1990; 66:49-55.

4 Krook JE, Moertel CG, Gunderson LL, Wieand HS, Collins RT, Beart RW, et al. Effective surgical adjuvant therapy for highrisk rectal carcinoma. N Engl f Med 1991;324:709-15.

5 Douglass HO, Moertel CG, Mayer RJ, Thomas PRM, Lindblad AS, Mittleman A et al Survival after post operative combinacion ireatment of rectal cancer. NEnglf Med 1986:315:1294-5.

EDrTor,-If local recurrence inevitably afflicted about a third of patients after apparently complete resection of rectal carcinoma, as $\mathrm{R} \mathrm{H}$ J Begent has every reason to write, given some published reports, then the adjuvant radiotherapy and chemotherapy that he recommends for Dukes's stage $B$ and $C$ tumours would make sense.' This outcome, however, may well be avoidable.

I recently examined the sequel in each of the 212 patients with rectal carcinoma under my care during 1985-91 and found no evidence of such depressing failure. Altogether 135 patients had had curative major resections; 41 had palliative removal; and 12 had borderline palliative excision, in which an adjacent structure (usually the uterus or part of the bladder wall) was removed en bloc with the specimen. Of the remainder, 18 had transanal excision and six no procedure. Only one patient was lost to follow up.

None of the patients who had curative resection had adjuvant treatment and local recurrence developed in only three cases; this could be attributed to failure of technique in two cases and to erroneous management in one. None of the patients who had "en bloc" resections received adjuvant treatment either; one developed recurrence-unsurprisingly, since tumour invasion of both the uterus and excised vaginal wall was confirmed on histological examination. Most of the patients who had palliative resections received postoperative radiotherapy; eight developed local recurrence. Twenty two of these 41 patients, however, died within six months of surgery. Similarly, one of 91 patients who had curative resections of tumour of the rectosigmoid during the same period, and one of 11 who had palliative resections, developed local recurrence, though again half died within six months.

Clearly, much hinges on definition and comparing like with like when excluding palliative resections and recognising local recurrence. I define palliative resection of tumour as either cutting or fracturing the tumour off an adjacent irremovable structure, or leaving peritoneal deposits seeded transcoelomically, and local recurrence as the reappearance of tumour at the original site. With these definitions, and if the principles of resection of colorectal cancer are followed-namely, total mesorectal excision for rectal tumours, elimination of exfoliated cancer cells from the bowel lumen above the upper clamps and below the lower clamps before transection, and abdominoperineal excision of rectum when the tumour is too low or poorly differentiated for restorative resectionthen my experience suggests that local recurrence will be so rare that adjuvant treatment is unnecessary.

W H F THOMSON

Gloucester Acute Unit, Gloucestershire Royal Hospital,

Gloucester GLI 3NN

1 Begent RHJ. Colorectal cancer. BMF 1992;305:246-9. (25 July.)

\section{Americans retreat on SI units}

EDIToR,-Magne Nylenna and Richard Smith criticise American doctors' retreat from using Système International (SI) units but do not strengthen their argument by comparing the introduction of a system of units with the global fight against serious disease. ${ }^{.}$The two problems are dissimilar, and it is unfair to make the comparison. Nylenna and Smith do not, however, explore why American readers prefer "conventional" units or mention the partial implementation of SI units in Britain.

Acceptance of SI units implies consistent use of both base units and derived units. Pressures should be expressed in pascals, temperatures in kelvin, and time in seconds. In practice we have a hybrid system of conventional units which often reflect the system used for analysis or measurement - for example, millimetres of mercury for blood pressure. Other compromises are made in expressing the amount of complex biological molecules in mass units rather than moles or as arbitrarily agreed units of biological activity.

If SI units are deemed more scientifically informative it is hard to imagine the day to day advantages in hospital wards of recording temperatures in kelvin, pressures in pascals, and time in seconds. Somewhere the importance of objectives has been overlooked. There seems little point in implementing a system that does not provide an advantage to either the provider or the recipient of health care.

There is no evidence that scientific thought is stifled when SI units are not used-indeed, most major advances in the pure sciences occurred without them. Perhaps the New England fournal of Medicine is still showing leadership qualities by provoking a debate on what we really want of our units in medicine.

\section{Lewisham Hospital}

J C TOWNSEND

London SE13 6LH

1 Nylenna M, Smith R. Americans retreat on SI units. BMF 1992;305:268. (1 August.)

EDIToR, - If Magne Nylenna and Richard Smith's editorial is a plea for standardisation of units and nomenclature' then British journals have lessons to learn. Picking an issue of the $B M \mathcal{F}(25$ July 1992) at random shows several anomalies.

(1) Page 203, column 1, paragraph 3: $1 / \mathrm{m}^{2 /}$ day-some use $L$ as the abbreviation for litre to avoid confusion with the numeral 1 . The superscript notation (i ${ }^{2}$ day ${ }^{1}$ ) is better for complex units. Indeed, some say that for Système International (SI) units the solidus should not be used for "per" at all.

(2) Page 203, column 2, paragraph 3: $n$-methylD-aspartate-should begin with $\mathrm{N}$ (for nitrogen) not $n$ (for normal).

(3) Page 215, abstract: $\mathrm{mm} \mathrm{Hg}$-should be pascals in SI.

(4) Page 216, column 1, paragraph 5: $\mathrm{mM}-$ should be mmoll ' in SI.

(5) Page 216, column 1, paragraph 5: $\mathrm{pH}-$ should be nmol 1 ' hydrogen ion in SI.

If Nylenna and Smith's response to any of the above is that "this is better for our readers" then they should reread the editorial in the New England fournal of Medicine that they criticise so strongly and have some sympathy for the Americans' predicament. ${ }^{2}$ We also question Nylenna and Smith's statement that "Britain ... could introduce SI units everywhere after broad consensus was reached." SI units date from 1960, yet in current British legislation blood and breath ethanol concentrations are cited in $\mathrm{mg}$ and $\mu \mathrm{g}$ per $100 \mathrm{ml}$ respectively. Indeed, the interface between clinical laboratory medicine and other disciplines such as pharmacology and toxicology was largely neglected when SI molar units were introduced in clinical biochemistry.

With SI units (in essence an extension of the metre-kilogram-second system) it is the interpretation that causes all the fuss. There are inconsistencies - for example, one of the base units, the kilogram, is a multiple of the gram. Nevertheless, the framework has stood the test of time, although production of different versions of SI units by different bodies is a continuing source of confusion. Standardisation of SI units is one step. Adoption of molar units to the exclusion of mass units is another step. While doses of drugs, for example, are still measured in mass units it is logical to report plasma concentrations in SI mass units (mgl ', etc) rather than in moles.

The $B M \mathcal{F}$ should lead by example not only in advocating SI units but also in ensuring that the associated conventions are applied sensibly and, if found wanting, are changed.

R J FLANAGAN

Pisons Unit,

Guy's and Lewisham NHS Trust,

London SE14 SER

L F PRESCOTT

Clinical Pharmacology Unit,

University Department of Medicine,

Royal Infirmary,

Edinburgh EH3 9YW

1 Nylenna M, Smith R. Americans retreat on SI units. BMF 1992;305:268. (1 August.)

2 Campion EW. A retreat from SI units. $N$ Engl f Med 1992; 327:49.

\section{Serotonin, gastric emptying, and dyspepsia}

EDITOR,-Functional disorders have important economic and social consequences. ${ }^{1}$ Thus A Chua and colleagues' observation of differences between selected dyspeptic subjects and controls in both solid phase gastric emptying and release of prolactin induced by buspirone is of great interest. ${ }^{2}$ The interpretation of work on functional bowel disorders is confounded by arbitrary definition of cases $^{3}$ and the high prevalence of symptoms in controls who do not present to a doctor. ${ }^{4}$ Explicit criteria for selecting cases and entry criteria are needed for both further research and extrapolation of findings to the clinic or general practice surgery. Unfortunately, Chua and colleagues give few data on the duration and severity of symptoms, or the incidence of other complaints. The proportion of dyspeptic subjects excluded by their complex organic screening process should have been given. There is also no indication of exactly how "formal psychiatric illness" was ruled out. Given the high prevalence of psychological dysfunction in such patients ${ }^{+}$these data are indispensable.

The response of prolactin to serotoninergic agonists has been studied in patients with primary psychiatric disorders. Enhanced release has been found in disorders related to anxiety. ${ }^{5}$ This may also be relevant to work on those labelled as having the postviral fatigue syndrome. ${ }^{6}$ Similar neuroendocrine responses are seen in the premenstrual syndrome, ${ }^{7}$ the postviral fatigue syndrome, ${ }^{6}$ and anxiety disorders. Can changes in stomach motility therefore be attributed to the putative hypersensitivity to serotonin? Do all these conditions produce similar complaints or changes in motility? Moreover, the prolactin response in Chua and colleagues' cases overlaps considerably with that in the controls, from which over half seem indistinguishable; the remainder of the cases are dominated by one particularly high responder. This erodes confidence in the idea that the phenomenon explains symptoms.

Gastric emptying may have been delayed by increased sympathetic tone mediated by anxiety. Alternatively, prolonged loss of appetite due to the patients' symptoms may have resulted in decreased 